\section{ACCURATELY CONTROL YOUR HANDPIECE SPEED}

The Optima MX INT system from BienAir provides a complete and reliable solution for your endodontic work.

Bien-Air's philosophy of 'click and work' is a new approach to your endodontic needs. The Optima MX is an interface that enables you to start treatment in a single click. This navigation system is impressively simple: it allows you to change the treatment settings in just a few clicks. You can perform your root treatments safely and with a significantly reduced risk of instrument breakage due to the auto reverse function.

With an easy to use, intuitive display, the Optima MX INT converts your air-driven system to an upgraded electric operation, allowing, for example, NiTi endodontics to be covered with a standard 1:1 contra-angled handpiece. Thanks to the unique performance of the motor and control systems most other procedures are covered with just two contra-angles (1:1 and 1:5), reducing the number of conventional instruments used in the surgery and saving time, bother and expense. The System can also be quickly and easily tailored to your individual requirements.

\section{Reader response number 60}

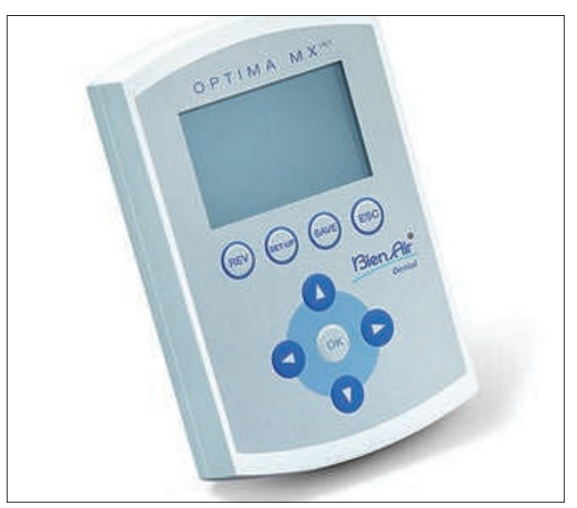

\section{SIMPLIFY YOUR COMPOSITE BONDING}

G-Bond is probably the fastest bonding agent on the market. It takes just 30 seconds from start to finish with no separate etching required. Simply apply G-Bond to cut enamel and dentine, leave for 10 seconds, blow dry thoroughly for 5 seconds and then cure for 10 seconds - all done!

The 'nano interaction zone' is created by two monomers that create a non-conventional interface with the available tooth minerals, resulting in extremely high bond strength. This HEMA free material will not absorb moisture and therefore will not discolour, will not degrade the collagen layer and is no risk to allergen sufferers.

G-Bond demineralises the tooth by less than 1 micron, leaving significant

\section{PREMIUM IMPLANT SOLUTION}

Over the past 30 years Straumann have developed their implant dentistry portfolio on a scientific foundation and continuously increase treatment safety.

It is not uncommon for cheap manufacturers to promote their products with price differences by comparing their undocumented, second generation products against the most expensive, high-end premium solutions such as Straumann's third-generation hydrophilic SLActive ${ }^{\circledR}$ surface.

Endorsed by more than 25 ongoing studies, SLActive ${ }^{\circledR}$ is one of the best investigated and well documented implant surfaces on the market.

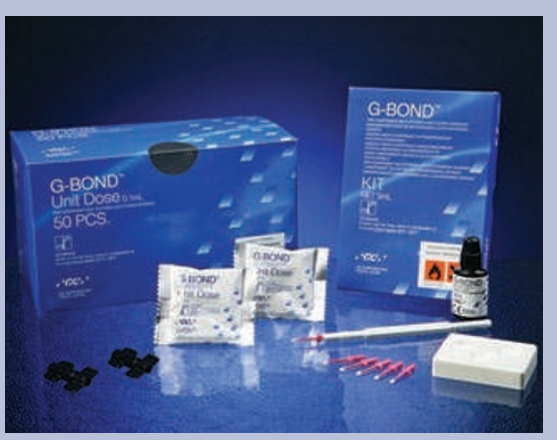

minerals available for the chemical adhesion process. As the dentinal tubules stay closed during the procedure there is little risk of sensitivity. The simultaneous demineralisation and monomer infiltration result in a better seal of the hybrid layer, resulting in less leakage and a long-term bond.

Reader response number 61

\title{
MARKET TOOTH WHITENING TO YOUR PATIENTS
}

With all the competition dental professionals face from 'over the counter' tooth whitening products, it is essential that marketing of this important cosmetic dental procedure is taken into high consideration by all members of your practice. A patient who has their teeth professionally whitened is likely to take more interest in their general dental health, resulting in subsequent frequent check-ups and additional dental restorative or cosmetic procedures alike.

To compliment SDI's Pola range of tooth whitening products and to better assist dental professionals and their staff to promote these procedures to
Without clinical substantiation, low price implants simply have no claim to equivalence. Even when it comes to simple design features and finish, the claim that a cheap implant is an equivalent alternative must be based on comparative long-term data to support it, which often is not the case.

Straumann offers great flexibility, for example in terms of prosthetic range and planning, with simple handling and workflow. These are just two of many elements of their value proposition, which, together with Straumann's lasting quality and service, explains why Straumann is a premium implant solution.

Reader response number 62 